\section{Morando com}

\section{meus avós:}

\section{as familias conviventes na perspectiva das crianças}

\author{
Viviendo con mis abuelos: \\ las familias convivientes en la \\ perspectiva de los niños
}

Living with my grandparents:

families living in the perspective of children

\section{Resumen}

El presente artículo se ocupa de las relaciones intergeneracionales entre abuelos y nietos niños en situaciones de cohabitación que constan de tres generaciones. Para ello, parte del relato de doce niños y niñas de edades entre los ocho y los diez años, de la clase media de la ciudad de Porto Alegre, al sur de Brasil. En este estudio, los niños van a discutir cómo se organizan estas casas, los roles que ocupan los diversos miembros y las redes de solidaridad entre las generaciones. Estas son realidades que constituyen la vida diaria de muchos niños, dejando marcas importantes en su infancia y en sus relaciones familiares.

\section{Palabras clave}

Infancia, abuelos, nietos, relaciones intergeneracionales, familias cohabitantes.

\section{Resumo}

0 presente artigo trata das relações intergeracionais entre avós e netos crianças em lares conviventes formados por três gerações. Para tanto, parte do relato de doze meninos e meninas, com idades entre oito e dez anos, pertencentes à classe média da cidade de Porto Alegre, região Sul do Brasil. Nesta pesquisa, as crianças discutem o modo como esses lares se organizam, os papéis ocupados por seus diferentes membros e as redes de solidariedade entre as gerações. São realidades que constituem o cotidiano de muitas crianças, deixando marcas importantes em suas infâncias e em suas relações familiares.

\section{Palavras chave}

Infância, avos, netos, relações intergeracionais, famílias conviventes.

\section{Abstract}

This article deals with intergenerational relationships between grandparents and grandchildren in threegeneration households. It is based on the report of twelve boys and girls, aged between eight and ten years, from the middle class of the city of Porto Alegre, southern Brazil. In this research project, the children discuss how these homes are organized, the roles played by some family members and the solidarity networks between the generations. Such realities constitute the daily life of many children, marking their childhood and their family relationships.

\section{Key words}

Childhood, grandparents, grandchildren, intergenerational relationships, living together families.

Fecha de recepción: 26 de marzo de 2012 Fecha de aprobación: 1 de agosto de 2012

El artículo presenta resultados de la investigación realizada como parte de la tesis doctoral titulada "Meus avós e eu: as relações intergeracionais entre avós e netos na perspectiva das crianças" (UFRGS, 2011), desarrollada com niños y niñas de classe media de la ciudad de Porto Alegre (Rio Grande do Sul, Brasil). 
A corresidência entre avós e netos é um fenômeno que tem aumentado nos últimos anos, sendo vivida por um número cada vez mais expressivo de crianças. Dados do Instituto Brasileiro de Geografia e Estatística apontam que 24,8\% dos idosos brasileiros vivem com filhos ou parentes e 37,9\% com cônjuges, filhos ou outros parentes, dentre os quais estão os netos (IBGE, 2004). Nos Estados Unidos, 9\% do total das crianças norte-americanas-ou seja, sete milhões de meninos e meninas- moram com seus avós. Destes, $22 \%$-ou pouco mais de um milhão e meio- vivem sem a presença dos pais (U.S. Census Bureau, 2010). Inúmeros fatores podem levar avós e netos a compartilharem a mesma casa. De um lado, a corresidência pode ser impulsionada por circunstâncias que envolvem a geração mais velha, tais como viuvez, separação, perda de autonomia física, idade avançada ou o recebimento de aposentadorias precárias; de outro, ela pode representar um pedido de ajuda da geração do meio, que frente ao desemprego, alto custo de vida, dificuldades financeiras, gravidez na adolescência, divórcio e cuidado dos filhos, solicita o suporte e o amparo familiar. Todavia, as situações de corresidência não trazem consequências apenas para os contextos de vida da primeira ou da segunda geração. A vida das crianças também é afetada pelo modo como esses lares se organizam, uma vez que elas estão sujeitas a um contato familiar mais verticalizado, marcado pela presença constante dos avós em seus cotidianos, e uma vez que os papéis sociais podem se alterar nesses contextos domésticos. Contudo, pouco se sabe sobre o modo como as crianças vivem nessas famílias, uma vez que grande parte dos estudos sobre o tema centra suas análises nos papéis assumidos pelas gerações mais velhas.

Este artigo busca subverter essa invisibilidade, discutindo como as crianças vivem e pensam suas infâncias em famílias conviventes formadas por três gerações -avós, filhos e netos- e analisando o modo como as relações entre avós e netos se dão nesses domicílios. Para tanto, parte do relato de doze meninos e meninas, com idades entre oito e dez anos, pertencentes à classe média alta da cidade de Porto Alegre, na região Sul do Brasil ${ }^{1}$. Por meio de entrevistas em trios, as crianças foram convidadas a falar sobre algumas das diferentes interfaces que constituem a

1 Este artigo traz dados oriundos de minha tese de doutorado, intitulada "Meus avós e eu: as relações intergeracionais entre avós e netos na perspectiva das crianças" (Ramos, 2011), na qual foram entrevistadas 36 crianças pertencentes a famílias nucleares, monoparentais, reconstituídas e conviventes. Para o presente artigo me dedico a analisar o modo como as relações intergeracionais se dão nos lares conviventes. Os nomes das crianças são fictícios e foram escolhidos por elas durante os momentos de entrevista. relação delas com seus avós em lares conviventes, abordando aspectos relacionados aos seus cotidianos familiares, às redes de suporte material e afetivo entre as gerações e aos papéis desenvolvidos pelos diferentes membros da família. Todavia, ao contarem sobre suas experiências e sobre os diferentes ângulos que compõem essa relação, as crianças não se utilizaram apenas da oralidade. Elas também fizeram uso da linguagem escrita e plástica, realizando desenhos sobre suas famílias, criando cartografias que representam os afetos e as distâncias geográficas entre seus membros e elaborando registros fotográficos que documentam os lares partilhados com seus avós. "Dar voz" às crianças nas pesquisas não significa apenas escutá-las enquanto expressão advinda meramente da fala, mas trabalhar com as diferentes linguagens que elas possuem. Os relatos das crianças são testemunhos de suas próprias biografias, e é axiomático, como nos lembra Scott, "[...] que apenas entrevistando crianças diretamente possamos compreender os seus mundos sociais" (Scott, 2008, p. 103).

\section{Dividindo o mesmo teto com os avós}

Entre avós e netos, a corresidência pode acontecer de duas maneiras: na ausência ou na presença de ao menos um genitor. Tais situações normalmente englobam motivações e circunstâncias de vida bastante distintas. No primeiro caso, os avós se encarregam do cuidado integral de seus netos, assumindo uma segunda carreira de pais. Essa configuração familiar tende a ocorrer quando os pais não podem ou não querem mais cuidar de seus filhos, delegando à primeira geração esse papel. De acordo com Pebley \& Rudkin (1999), o cuidado exclusivo por parte dos avós acontece principalmente nos casos em que os pais estão divorciados, tiveram uma gravidez precoce, estão presos, envolvidos com o consumo de drogas e álcool ou são portadores de alguma doença crônica. Nos países onde a prevalência do HIV/AIDS é elevada, por exemplo, são os avós que têm cuidado de seus filhos infectados e de seus netos. Uma pesquisa feita pela Organização Mundial de Saúde (OMS, 2000) aponta que em Zimbábue, cerca de $72 \%$ dos cuidadores de pessoas contaminadas com o vírus tinham mais de 60 anos. Dentre os doentes, 40\% eram filhos e 28,2\% eram netos do chefe da família. Dos órfãos, 80,5\% eram cuidados pelos avós (Camarano et al., 2004).

No contexto norte-americano, onde entre os domicílios que trazem a presença dos avós, aquele que mais cresce é onde as crianças não possuem nenhum dos pais presentes, os avós também têm se mostrado figuras decisivas no cuidado dos netos. Segundo dados do U.S. Census Bureau, entre 1990 e 1997, o número de famílias conviventes com avós,

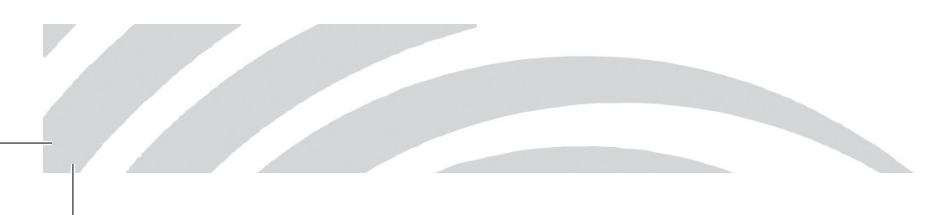


filhos e netos cresceu em 13\%, enquanto que, nas famílias compostas apenas por avós e netos, essa porcentagem era de 39\% (Casper \& Bryson, 1998). Quando os avós assumem o papel de cuidadores primários, eles precisam adotar uma postura mais autoritária e disciplinadora em relação aos netos, o que faz com que eles muitas vezes percam o seu "papel tradicional" de avô.

De acordo com o estudo de Landry-Meyer \& Newman (2004), feito com 47 avós norte-americanos que coabitavam com seus netos sem a geração do meio, grande parte deles reportava viver uma espécie de "conflito de regra", no qual se sentiam privados de experimentar a vivência livre e fluida da avosidade em prol das tarefas cotidianas da parentalidade. Essas relações eram marcadas por dificuldades de convívio com os netos, que muitas vezes não aceitavam a posição ocupada pelos avós, principalmente quando esses não possuíam a sua custódia legal. Alguns avós também tinham dúvidas quanto às suas habilidades parentais, uma vez que se achavam velhos demais para tornarem-se "pais", acreditavam não ter mais o mesmo nível de energia de outrora e tinham medo de fazer os mesmos erros que julgavam ter cometido na educação de seus próprios filhos. A entrada nesse papel normalmente acontece de forma abrupta, e se por um lado os avós podem se sentir despreparados e inseguros para assumir a responsabilidade integral de seus descendentes, por outro os netos também podem se sentir resistentes em aceitar a tutela exclusiva de seus avós.

Mas a corresidência entre avós e netos também pode acontecer na presença dos pais. Na verdade, grande parte das moradias em que avós e netos corresidentes é composta pelo convívio de três gerações. Nos Estados Unidos, por exemplo, elas somam 78\% do total de lares em que há avós e netos residindo
(U.S. Census Bureau, 2010). A corresidência entre três gerações pode significar o prolongamento de um processo de coabitação, no qual os filhos geram seus próprios filhos sem nunca terem saído efetivamente da casa dos pais; ou um processo de re-coabitação, que ocorre quando pais e filhos voltam a dividir o mesmo domicílio (Pebley \& Rudkin, 1999; Peixoto, 2004). Todas as crianças que participaram desta pesquisa viviam em domicílios compostos por três gerações, sendo que sete delas eram oriundas de famílias coabitantes e cinco de famílias re-coabitantes. Entre as primeiras, o principal motivo da coabitação parece ter sido a gravidez precoce das mães: seis delas tiveram seus filhos entre os 16 e os 24 anos, tendo permanecido, da infância à fase adulta, na casa dos pais, como nos explicam os próprios meninos e meninas entrevistados:

Fernando [10 anos] - A minha mãe, ela sempre morou lá, a minha avó também. E daí eu nasci e minha irmã também, e daí a gente morou aí junto.

Jaqueline [10 anos] - A gente sempre morou junto, minha avó teve a minha mãe, minha mãe cresceu lá e eu cresci lá.

Fernanda [9 anos] - A minha mãe morava com a minha avó desde pequena e sempre na mesma casa. Faz um tempão que a gente mora naquela casa! Eu moro lá desde pequena, desde que eu nasci!

Luck [9 anos] - A minha mãe nasceu em Garibaldi, aí eles [a família da mãe] vieram morar em um outro prédio. Aí eles se mudaram pra cá e eu nasci no ano seguinte. E é isso, eu tô aqui até hoje.

Ashley [9 anos] - Eu sempre morei com meus avós, desde pequenininha. [...] Eu acho que a minha mãe nunca saiu de casa!

\section{Gráfico 1}

Brasil: proporção de mulheres jovens que tiveram fillhos e residiam na casa dos pais - 1980 e 2000

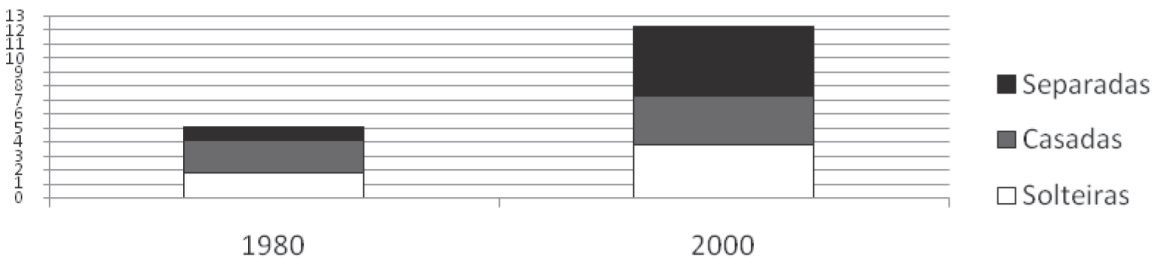


Alice afirma morar com a sua avó: "Pra mim, eu moro com a minha vó, porque a minha vó mora no mesmo terreno que eu, então eu vejo ela todos os dias. É só atravessar um terreninho que é bem pequenininho que eu tô lá"3

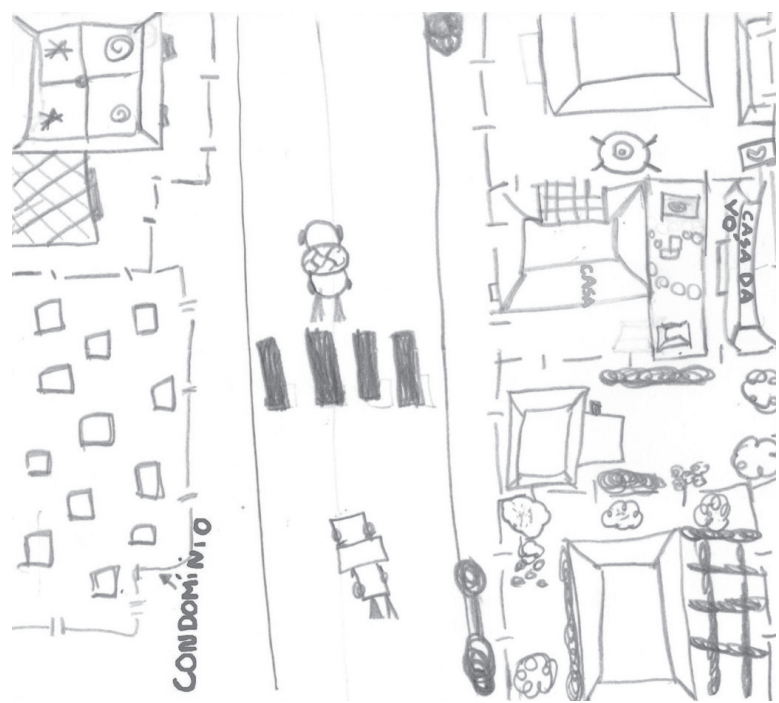

Figura 3: Desenho do condomínio (à esquerda) onde Alice morava com seus pais antes de sua família se mudar para o mesmo terreno que sua avó materna (à direita).

A ajuda na aquisição da casa própria também foi recebida pela família de Nycolle (8 anos), que mora em um apartamento cedido por seu avô materno, e pela família de Leonardo ( 8 anos), que mora no piso superior da casa de sua avó materna:

Nycolle [8 anos] - Minha família foi morar com meu vô e com a minha avó quando eu nasci. Meu vô deu o apartamento debaixo da casa dele pra eu morar com meus pais quando eu saí do hospital.

Leonardo [8 anos] - A minha vó comprou o terreno e pediu pra construírem a casa, o canil e a garagem. Na verdade o canil não. Daí a minha mãe foi morar com a minha vó e o meu pai também. Daí eles construíram a parte de cima juntos e o canil também. Agora meus pais são separados e eu moro com a minha mãe e a minha irmã na parte de cima e a minha vó mora na parte de baixo.

Com o intuito de abrigar três gerações, as famílias conviventes muitas vezes precisam juntar esforços para adaptar e reestruturar seus lares. Algumas

3 A assunção de morar junto com os avós, mesmo quando esses não dividem explicitamente a mesma casa, é significada pelas crianças de forma diferenciada. Enquanto algumas crianças interpretam essa relação como "corresidência", outras a conceituam como "vizinhança". Nesta pesquisa, as crianças corresidentes são aquelas que se autodenominaram assim, mesmo quando elas e seus avós não dividiam explicitamente a mesma casa. vezes elas constroem novas repartições, criando espaços nas laterais, nos fundos ou na parte superior de seus domicílios, como bem exemplificaram os depoimentos de Alice, Nycolle e Leonardo; outras vezes, as residências não comportam esse tipo de reforma e precisam ser alteradas exclusivamente no seu interior. Nesses casos, a adaptação pode ser ainda maior, uma vez que nem sempre as famílias possuem lares espaçosos para acolher seus integrantes e uma vez que a vinda de novos membros modifica tanto as práticas cotidianas dos avós, quanto dos filhos e dos netos corresidentes.

\section{Reorganizando o interior da casa}

Voltemos ao caso de Alice (10 anos), que antes de morar na casa construída na parte dianteira do terreno de sua avó materna, morou por alguns meses na casa dos fundos, habitada exclusivamente por sua avó. Em seu depoimento, Alice conta como ela e sua família se ajustaram às condições do domicílio: "A casa da minha avó tem dois quartos. Antes da gente se mudar, a gente [pai, mãe, ela e a irmã] ficou morando todo apertadinho em um deles e no outro a minha vó é quem ficava. Não era muito fácil. A gente fica bem espremidinho", relata a menina. José (8 anos), que foi morar com o pai e a avó paterna alguns anos depois que seus pais se separaram, conta como eles reestruturam a casa para recebê-lo: "Eu tenho um quarto só pra mim. Ali era um quarto que só tinha uns negócios da minha vó tudo jogado assim, era um quarto que ninguém usava. Aí arrumaram tudo e aí deu. Fizeram o meu quarto" (Figura 4) ${ }^{4}$.

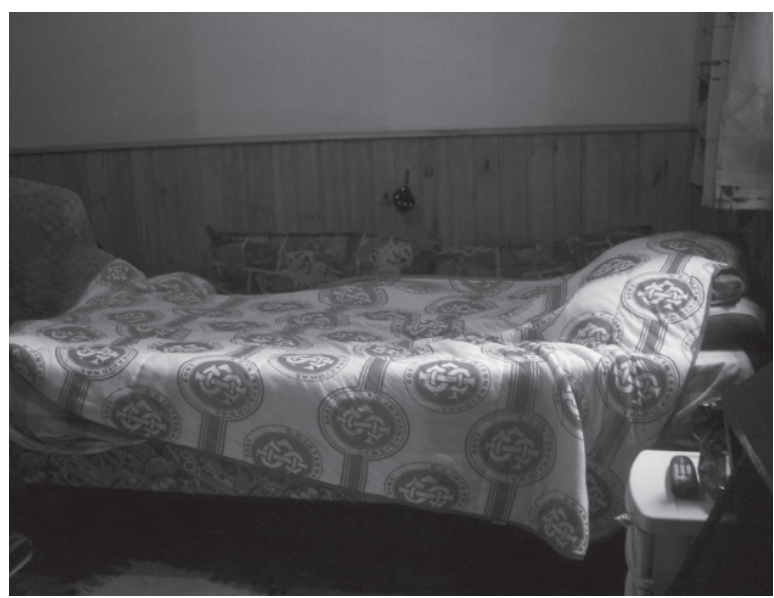

Figura 4: Foto do quarto de José na casa da avó paterna, que mostra a adaptação de um antigo cômodo para receber o menino.

4 As imagens fotográficas aqui representadas foram feitas pelas crianças durante os encontros de pesquisa. Essas imagens falam de seus lugares preferidos na casa dos avós conviventes, relatando partes importantes de seus cotidianos familiares. 
O mesmo ocorreu com Natasha ( 9 anos), que se mudou para a casa da avó com a sua mãe quando seus pais se divorciaram e sua mãe ficou desempregada (Figura 5):

Natasha [9 anos] - Antes da gente chegar a minha vó ficava lá no meu quarto e ali onde é o quarto dela era a sala. É que daí mudou tudo quando eu cheguei com a minha mãe. Quando a gente chegou lá, ela se mudou para cá, arrumou um cantinho pra botar a cama dela e deu o quarto dela pra gente.

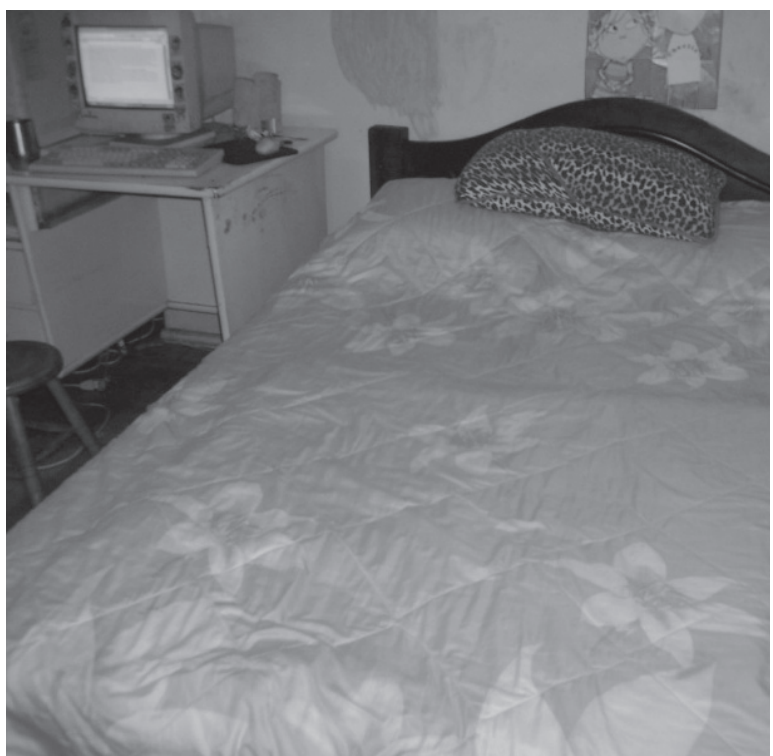

Figura 5: Foto do quarto de Natasha na casa da avó materna. Ela divide a cama com a mãe enquanto a vó dorme na sala.

$\mathrm{Na}$ fotografia feita por Natasha, podemos ver o quarto que era da avó transformado em um quarto para a filha e a neta: "Aqui é o meu quarto. Eu divido com a minha mãe. A gente dorme na mesma cama", explica a menina. Dormir na mesma cama ou no mesmo quarto que os pais é a realidade cotidiana de muitas crianças que moram em lares conviventes. Esse também é o caso de Fernanda ( 9 anos), que divide o quarto com a mãe desde que era pequena (Figura 6), ou de Carol (9 anos), que mora metade da semana com o pai e a outra metade com a avó materna e a mãe (Figura 7). Tanto a mãe de Fernanda, quanto a mãe de Carol, transformaram seus próprios quartos para receber as filhas:

Fernanda [9 anos, sobre a Figura 6] - Eu e a minha mãe dormimos nesse quarto e a minha vó dorme no outro quarto. Sempre foi assim, desde que eu era pequenininha.

Carol [9 anos, sobre a Figura 7] - Aqui é a minha cama. Aqui do lado, dá pra ver, tem outra cama. É um quarto dividido. Eu divido com a minha mãe e a minha vó dorme no quarto dela.

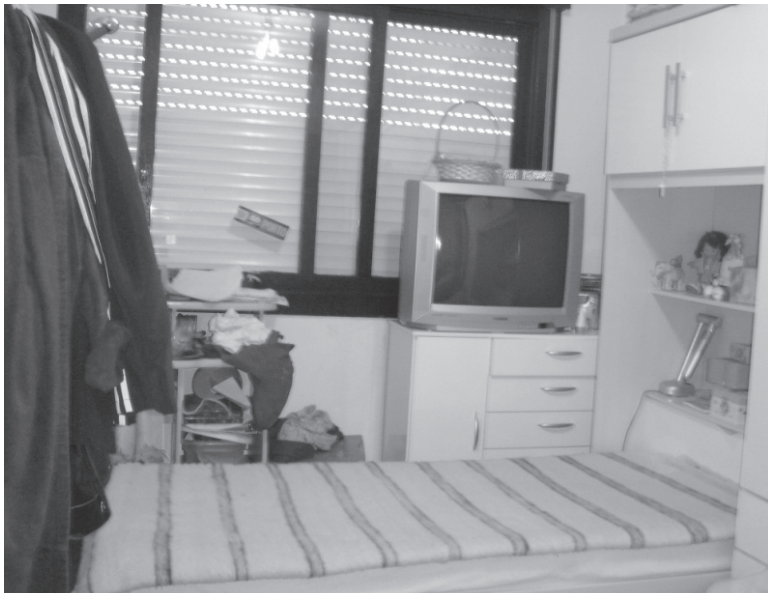

Figura 6: Foto do quarto de Fernanda na casa da avó materna. Ela divide o quarto com a mãe enquanto a vó dorme no segundo dormitório da casa.

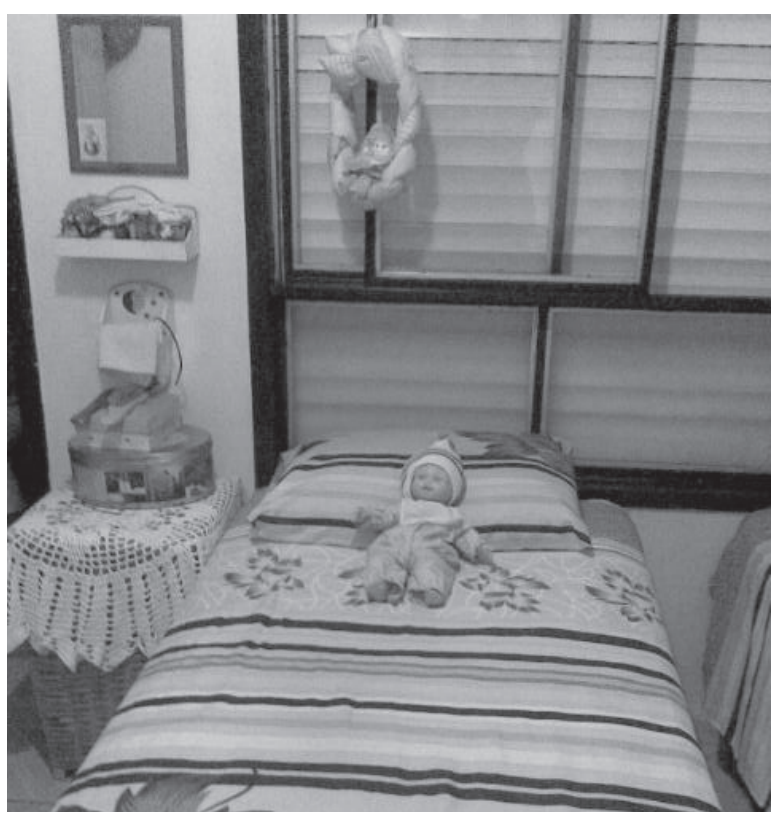

Figura 7: Foto do quarto de Carol na casa da avó materna. Ela divide o quarto com a mãe enquanto a vó dorme no segundo dormitório da casa

Nos processos de corresidência, é o proprietário do imóvel quem normalmente acolhe os demais integrantes, cedendo parte de sua casa ou permitindo a construção de um novo lar acoplado ao seu domicílio. Dados do IBGE apontam que a maior proporção de pessoas que moram em domicílios próprios e quitados encontra-se entre os idosos (Camarano, Kanso \& Mello, 2004), o que faz com que eles recebam, na maioria dos casos, seus filhos e netos em casa. De acordo com Peixoto \& Luz (2007), a coabitação entre as gerações tem sido uma prática utilizada não apenas pelas classes populares como, também, pela própria classe média, o que pode ser claramente observado neste estudo. Segundo essas autoras, as gerações mais 
velhas foram favorecidas por um período de crescimento econômico e por programas governamentais (a exemplo do Banco Nacional de Habitação) que facilitavam o financiamento da casa própria, uma vez que as taxas de juros eram reguladas de acordo com os reajustes salariais. Com a extinção desses programas e com as altas taxas de juros dos financiamentos privados, os jovens das camadas médias começaram a ter dificuldades em adquirir um imóvel, o que se tornou ainda mais difícil para as classes populares.

A criação do programa Minha Casa, Minha Vida ${ }^{5}$, em 2009, começou a alterar esse quadro, uma vez que o Governo Federal facilitou o financiamento da casa própria para as famílias que possuíam renda de até dez salários mínimos, tendo a meta de construir um milhão de casas. Todavia, além da questão da habitação, somam-se à situação dos jovens outros atravessamentos, como o maior tempo de escolarização, os elevados índices de desemprego nesta faixa etária e os próprios obstáculos enfrentados no processo de inserção no mercado de trabalho. Segundo a Organização Internacional do Trabalho, mesmo que nos últimos anos o Brasil tenha experimentado uma ligeira diminuição na taxa de desemprego, estima-se que 3,5 milhões de jovens com idades entre 16 e 24 anos ainda estejam desempregados, o que representa cerca de $45 \%$ da força de trabalho nacional (OIT, 2011). Nesses casos, a corresidência torna-se uma estratégia familiar importante, que permite a transferência de apoio entre as gerações.

Essa também parece ser a realidade das famílias conviventes aqui estudadas, uma vez que as situações de corresidência foram impulsionadas principalmente pelas necessidades -gravidez precoce, separação, divórcio, desemprego, aluguéis elevados, ajuda na aquisição da casa própria- da segunda geração. No Brasil, entre as famílias que possuem idosos residindo (26\% dos domicílios brasileiros), 86\% delas são chefiadas por idosos. Isso significa que na maioria das vezes eles não são apenas os proprietários dos imóveis, como, também, os grandes responsáveis pela manutenção da economia doméstica, contribuindo com cerca de $70 \%$ da renda familiar: 73,8\% quando o chefe é homem e $66,4 \%$ quando o chefe é mulher (Camarano, 2006). Na pesquisa realizada pela Fundação Perseu Abramo/SESC (2007) sobre os idosos brasileiros, esse fato também foi evidenciado:

5 O programa Minha Casa, Minha Vida foi criado pelo governo brasileiro como forma de amenizar o déficit habitacional do país. 0 programa possibilita o financiamento da residência para pessoas incluídas em três faixas salariais: de zero a três salários mínimos (até $\mathrm{R} \$ 1.530,00$ ), de três a seis salários mínimos (de $\mathrm{R} \$ 1.530,00$ até $\mathrm{R} \$ 3.060,00$ ) e de seis a dez salários mínimos (de $\mathrm{R} \$ 3.060,00$ até $\mathrm{R} \$ 5.450,00$ ). constatou-se que sete em cada dez idosos são chefes de família e que dois terços dos 5.561 municípios do país têm a economia sustentada pelos mais velhos. Tal situação aponta uma mudança no "papel tradicional" do idoso, que passa de dependente para provedor de boa parte do orçamento familiar.

A corresidência tira muitas famílias da monoparentalidade e dos riscos de pobreza, aumentando os anos de estudo de filhos e netos e diminuindo a exposição das crianças ao trabalho infantil. Embora o maior número de indivíduos corresidentes não signifique o aumento da renda familiar, os estudos demográficos mostram que as famílias brasileiras que contêm idosos parecem estar em melhores condições econômicas que as demais: "As que não contêm idosos apresentam uma proporção de famílias pobres quase duas vezes mais elevada que as que contêm" (Camarano, Kanso \& Mello, 2004, p. 59). Como os rendimentos da população idosa situam-se em um patamar mais elevado que os da população jovem -eles só são menores do que os da população de 40 a 59 anos-, são os idosos que oferecem grande parte do suporte econômico às suas famílias, ajudando de forma determinante seus filhos e netos. E embora os benefícios da seguridade social representem uma fração importante do orçamento familiar, Peixoto (2004) destaca que muitos idosos precisam continuar trabalhando, mesmo depois de aposentados, como forma de garantir os padrões de vida e as redes de solidariedade familiar. Mas, como as relações intergeracionais se dão nos famílias conviventes? Como as crianças avaliam as relações que elas estabelecem com seus avós nesses domicílios?

\section{Sobre as relações intergeracionais em lares conviventes}

As relações entre avós e netos coabitantes tendem a ser muito intensas: as crianças mostram estar não apenas fisicamente, como emocionalmente próximas de seus avós, sentindo-se acolhidas e cuidadas por eles. A convivência incita a intimidade e fortifica os laços entre as gerações, como nos mostra Jaqueline (10 anos) em seu depoimento:

Jaqueline [10 anos] - Eu gosto das minhas duas avós, mas dessa aqui [corresidente] eu gosto um pouquinho mais, porque eu sei o que ela faz pra mim, ela faz um monte de coisa pra mim, faz um monte de favor, [...] e a minha vó paterna eu não conheço tanto ela. Essa aqui eu conheço mais.

Ashley (9 anos) também diz gostar mais da avó que mora com ela: "Eu gosto mais dela porque eu tô sempre mais com ela, eu sei da vida dela, ela sabe da minha e porque a gente se vê mais!", exclama a me- 
nina. A intimidade também abre os laços da afeição, numa relação em que avós e netos não apenas convivem, como são muitas vezes amigos e confidentes: "Eu gosto mais dos meus avós maternos porque eu convivo mais com eles e tem muita coisa que eu falo só pra minha vó", conta Luck ( 9 anos). Já Leonardo (8 anos), ao realizar a atividade cartográfica ${ }^{6}$ durante os encontros da pesquisa e pintar os corações que representavam a sua afetividade em relação à avó convivente, pinta súbito três corações e exclama: "Essa aqui eu não tenho dúvida! Essa é muito minha amiga e me ajuda em tudo!". Algumas vezes as crianças avaliam que três corações não são suficientes para expressar todo o afeto que sentem, aumentando, espontaneamente, o seu número:
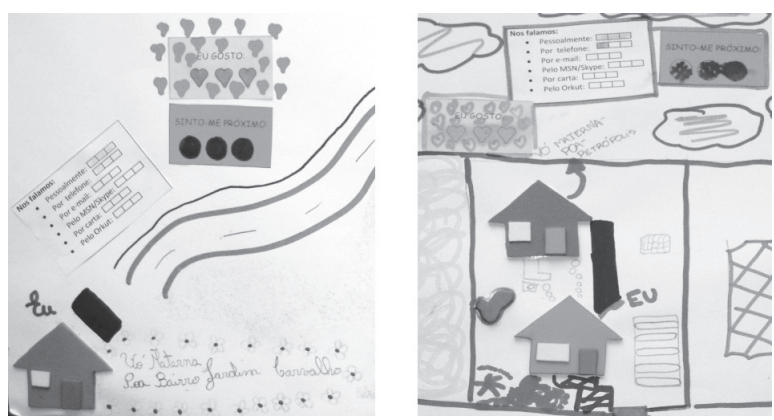

Figura 8: Da esquerda para a direita: fragmento das representações cartográficas de Jaqueline e Alice, nas quais podemos observar o grande número de corações pintados aos avós conviventes.

A convivência diária também permite que avós e netos sejam parceiros de múltiplas atividades, o que reforça a afeição, as redes de cuidado e a criação de vínculos entre eles. Muitas vezes sob a responsabilidade dos avós, principalmente quando seus pais trabalham ou estudam, são para eles que as crianças pedem socorro quando precisam de alguma ajuda, e é na companhia deles que muitas brincam e fazem o tema da escola:

Alice [10 anos] - Sempre que eu tô na escola e eu preciso de alguma coisa, não é pra minha mãe que eu ligo, é pra minha vó... quando eu me sinto mal, por exemplo, porque a minha mãe trabalha e, mesmo assim, mesmo em casa, é a minha vó que sempre me ajuda!

6 A representação cartográfica refere-se a um mapa das distâncias, afetos e intensidade do contato entre avós e netos elaborados pelas crianças durante os momentos de entrevista. Uma das atividades da cartografia consistia em pintar corações (de um a três) que expressassem o quanto as crianças sentiam que gostavam de seus avós. Ao pintarem um coração as crianças representavam que gostavam "pouco"; ao pintarem dois, que gostavam "médio" e, ao pintarem três, que gostavam "muito".
Jaqueline [10 anos] - A minha vó fica comigo daí eu não fico sozinha em casa. Se eu preciso de alguma ajuda, eu sei que ela tá ali, do meu lado!

Além disso, existem diferenças importantes no modo como os avós e os pais ajudam as crianças em suas tarefas escolares, o que faz com muitas vezes eles sejam eleitas para essa função: "As mães não sabem explicar!”, conta Fernanda (9 anos), “[...] parece que elas se irritam com a gente! $A$ minha vó explica muuuito melhor! A minha mãe explica, mas parece que ela explica coisas que eu não consigo entender! E a minha vó... ela explica beeeeem devagar!". O mesmo acontece com Fernando (10 anos), que prefere a ajuda de sua avó convivente, de 75 anos, na realização dos temas escolares: "A minha mãe me ajuda, mas ela explica coisas que eu não entendo! Daí eu acho que às vezes a minha vó explica melhor!".

Mas já se passaram alguns anos desde que os avós eram crianças e frequentavam os bancos escolares. Por isso, nem sempre eles conseguem lembrar-se das regras gramaticais da língua portuguesa ou de como resolver uma expressão numérica. Por outro lado, como nos lembra Amanda (9 anos), "[...] tem matérias que têm descobertas, como a Biologia, que tem um monte de novidades pra contar pra eles porque eles não aprenderam e tudo mudou". Porque os tempos mudaram e a forma de ensinar certos conteúdos ou mesmo o que ensinar também se modificou, é que alguns avós podem aprender com as crianças nessas situações. Nos desenhos abaixo (Figura 9 e 10), feitos por Fernando (10 anos), podemos perceber que esse é um processo coeducativo, no qual a sua avó lhe ensina o que ele não sabe, mas no qual ele também ensina à sua avó as coisas que ela não sabe. Por isso, apesar de seus desenhos serem aparentemente iguais -tanto ele quanto sua avó estão representados com a mesma roupa, com o mesmo caderno e sentados na mesma cadeira, um de frente para o outro-, no primeiro desenho a palavra está com a sua avó e, no segundo, está com o neto. 0 processo de aprendizagem é interativo e simétrico: ambos sabem coisas diferentes e ambos podem aprender e ensinar. Como pontua Oliveira,

[...] não é apenas uma geração que dá algo de si enquanto a outra, passivamente, fica sendo receptora inerte das dádivas. Essa linearidade tolda o movimento e impede a visualização das influencias recíprocas. Em outras palavras, não se trata apenas da passagem de sabedorias dos mais velhos para as crianças. Estas também transmitem muito aos mais velhos. (Oliveira, 2007, p.8). 


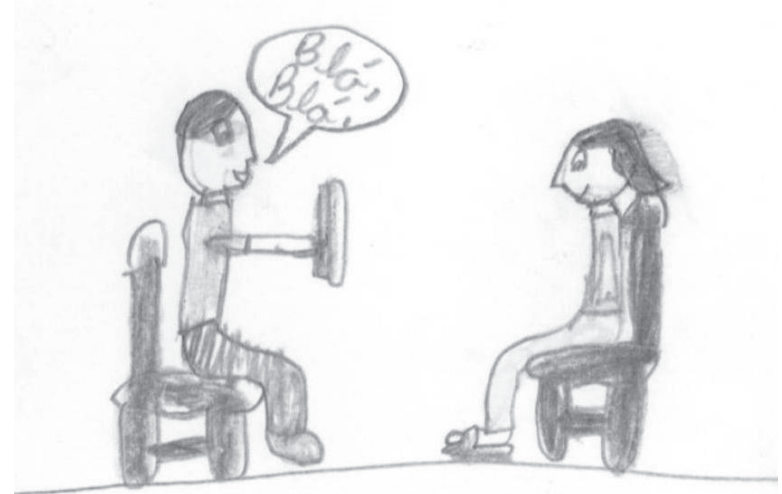

Figura 9: Desenho de Fernando: “A minha vó tá me ensinando as coisas que ela sabe".

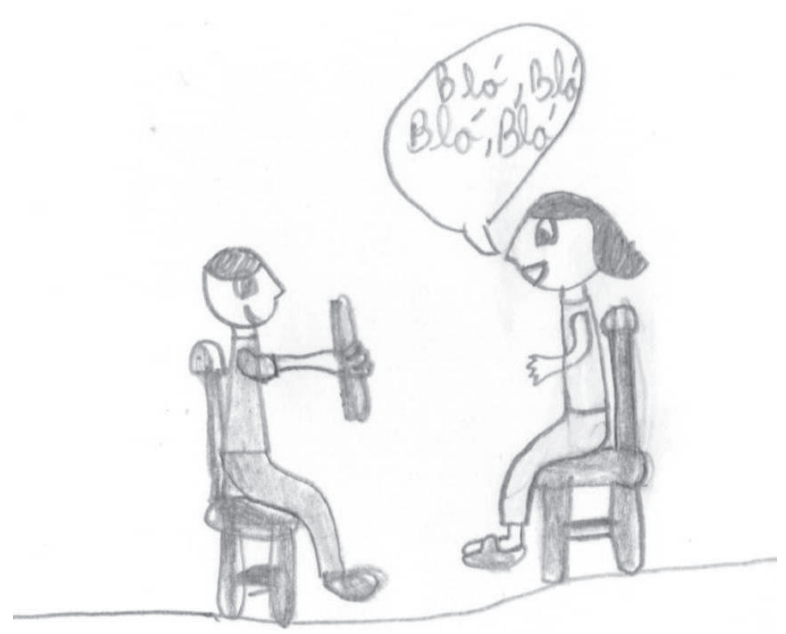

Figura 10: Desenho de Fernando: "Eu estou ensinando as coisas que eu aprendi na escola"

Esse processo também ocorre nos momentos de brincadeira. De um lado, as crianças socializam seus avós nas "brincadeiras de hoje em dia", apresentando a eles novas músicas, novos jogos e um amplo leque de brinquedos, como os jogos eletrônicos. De outro, os avós socializam seus netos nas "brincadeiras de antigamente", trazendo para a roda os jogos de carta, os jogos de tabuleiro e os brinquedos feitos à mão. São relações de reciprocidade, também encontradas nas situações de cuidado. Engana-se quem pensa que são apenas os avós que cuidam dos netos enquanto esses estão sob sua responsabilidade. Em seus depoimen- tos, as crianças revelam que elas também oferecem ajuda, cuidando da casa, levando os chinelos para os avós, fazendo massagem nas partes doloridas de seus corpos, levando as sacolas do supermercado ou servindo de apoio enquanto eles caminham pela casa. Durante esses momentos, as crianças são introduzidas ao processo de envelhecimento, o que faz com que elas não apenas saibam o que significa nascer e crescer, mas tornar-se velho e frágil.

Jaqueline [10 anos] - Outro dia, tava eu e a minha vó em casa e eu ajudei ela. Ela foi separar os cachorros que estavam brigando e um deles mordeu ela. Abriu o braço da minha vó. Aí, quando eu vi, eu chamei um taxi correndo pra levar ela pro hospital. E desde aquele dia eu fico fazendo o curativo na minha vó.

José [8 anos] - Às vezes os avós ficam esquecidos do que eles fazem e as crianças podem ajudar eles, podem ajudar eles a se lembrar das coisas... A gente pode cuidar, fazer o que eles nos pedirem. A gente pode ajudar! Se a minha vó quer, eu levo pra ela um copo de água, às vezes eu também vou buscar os chinelos...

Mas ocupariam os avós conviventes um lugar parental na vida das crianças, como normalmente ocorre nas famílias formadas exclusivamente por avós e netos? Ou eles conseguiriam preservar a sua "identidade" de avós? Como as crianças interpretam essas relações? Para elas, avós e pais têm posturas e papéis diferentes em suas famílias?

\section{Pais ou avós?}

Para as crianças, avós e pais conviventes ocupam lugares diferenciados na dinâmica familiar. De um modo geral, elas parecem vivenciar momentos bastante tranquilos na companhia de seus avós e esses parecem ocupar um papel mais secundário -mas não menos importante- na sua educação. Para Alice (10 anos), o papel de cuidador principal é assumido pelos pais: "Os nossos avós são nossos segundos pais. Quando os nossos pais não estão, então eles são os nossos responsáveis". 0 mesmo acontece com Fernanda (9 anos), que mora com a mãe e a avó: "A primeira mãe é a nossa mãe verdadeira e a nossa segunda mãe é a nossa avó. Eu tento resolver tudo com a minha mãe". Como argumentam Pebley \& Rudkin, "[...] viver com os avós em um residência de três gerações não necessariamente implica que os avós sejam profundamente envolvidos no cuidado [e na educação] dos netos" (Pebley \& Rudkin, 1999, p. 220). O estudo de Goodman (2007) feito com 376 avós norte-americanas que coabitavam com seus filhos e netos também mostrou que, na maioria das vezes, os pais assumiam 


\section{Considerações Finais}

Para as crianças que moram em lares conviventes, seus avós não são apenas figuras ascendentes. Eles fazem parte da sua família mais restrita. Ao representarem suas famílias, todas elas incluem seus avós coabitantes em seus desenhos, o que não fazem com aqueles que não corresidem com elas (Figura 11). Essas motivações estão vinculadas principalmente aos limites do domicílio, que indicam, ao menos em parte, "quem pertence" e "quem não pertence" à fa-

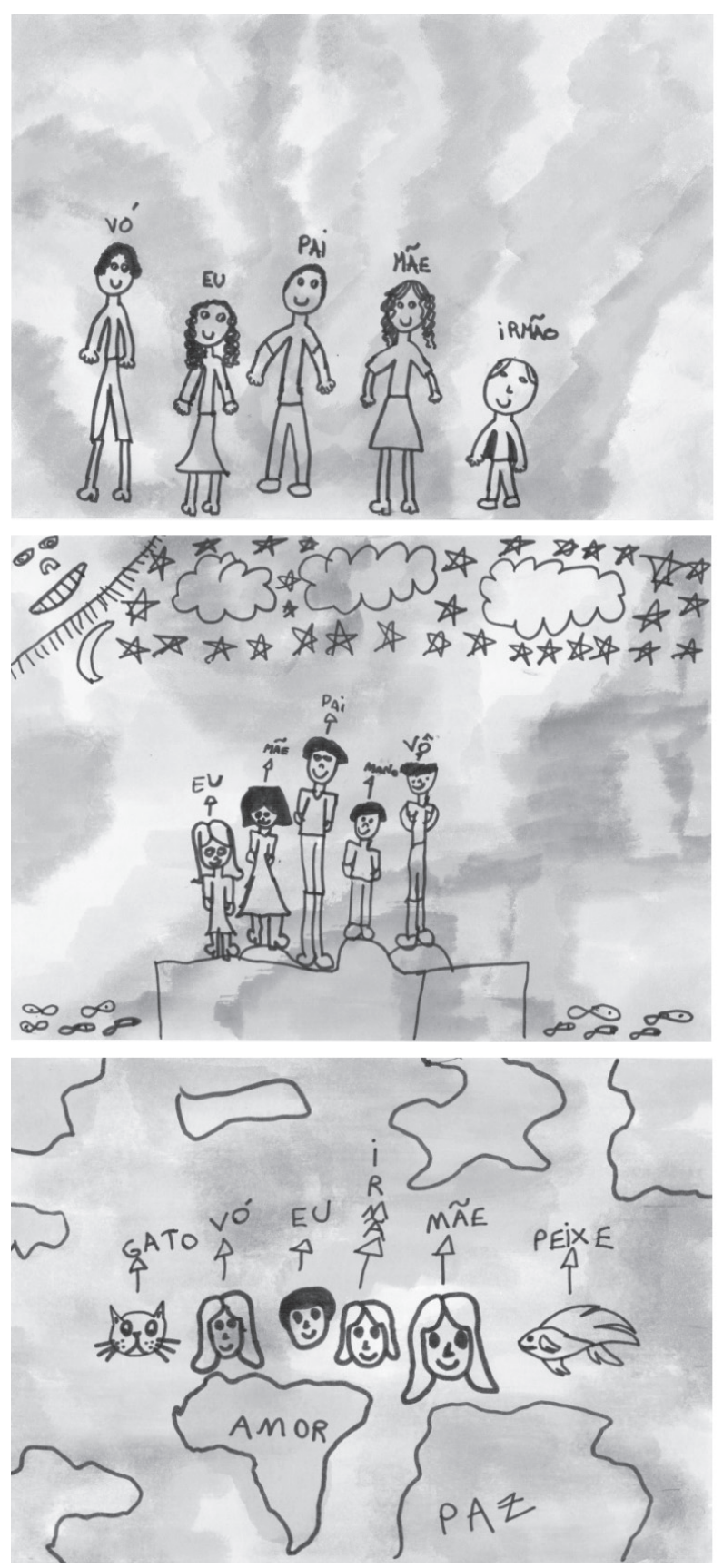

mília: "Eu desenhei essas pessoas porque elas moram comigo e eu fico mais próxima delas. São aquelas que estão mais perto de mim", diz Jaqueline (10 anos), que desenhou sua avó materna, mas não a paterna. Para Nycolle (8 anos), as pessoas que fazem parte da sua família são aquelas que moram com ela: "São as que eu vejo todos os dias. Às vezes a gente vê elas passando. Elas também almoçam com a gente, jantam.... Por isso a sua avó materna, que se separou recentemente de seu avô, não foi incluída em seu desenho, assim como a avó paterna, que mora em outra cidade. Leo-

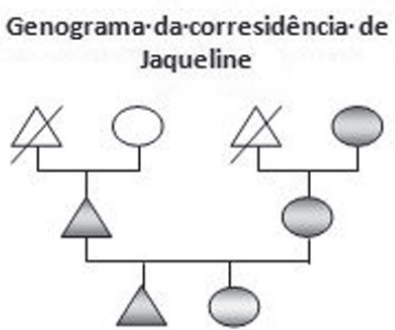

Genograma·da·corresidência·de Nycolle

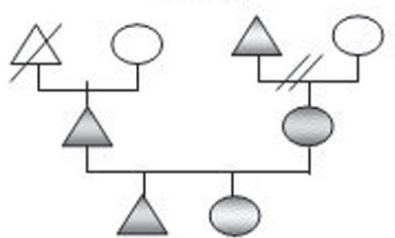

Genograma·da·corresidência·de Leonardo

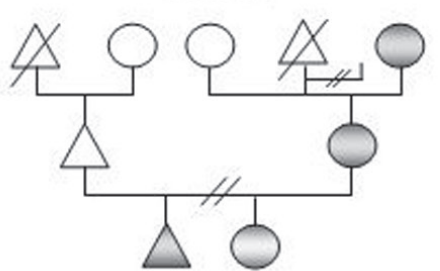

Figura 11: De cima para baixo, desenhos das famílias de Jaqueline, Nycolle e Leonardo com seus respectivos genogramas, nos quais podemos ver apenas a inclusão dos avós coabitantes e a exclusão dos avós não corresidentes. 
nardo (8 anos), que desenhou sua avó materna, mas não suas outras duas avós, diz tê-la desenhado “[...] porque só ela mora [com ele] e é da [sua] família. [...] Das outras duas eu não sou tão próximo", explica.

As fortes redes de suporte e cuidado existentes nos lares conviventes mostram que a família não está desagregada. Como bem aponta Attias-Donfut (2002), as solidariedades existem, feitas nas trocas de bens e serviços. $\mathrm{O}$ apoio oferecido por esses avós no cuidado dos filhos e dos netos representa uma forma importante de suprir as necessidades familiares, criando alternativas às dificuldades de vida e à escassa ou inadequada provisão oferecida pelo Estado. Especialmente entre as mulheres, a ajuda dada à jovem mãe representa um suporte à sua realização profissional, testemunhando uma solidariedade feminina na busca pela inserção no mercado de trabalho. Cabe lembrar que este estudo foi desenvolvido com crianças de classe média, que também têm juntando esforços para rearranjar os tempos e os espaços frente a situações intempestivas. A ajuda dada pela geração mais velha nas famílias tem sido tão importante, que muitas vezes os limites domiciliares entre avós e netos não-corresidentes também se borram. Com quem mora uma criança que passa o dia na casa dos avós, voltando para a "sua residência" apenas à noite? Seria ela uma criança de uma família convivente? Moraria ela com seus pais ou com seus avós?

Melissa (10 anos), que mora com a mãe, mas passa o dia inteiro na casa dos avós paternos, ficando lá pela manhã, durante o almoço e depois da escola, vive esse esfumaçamento de fronteiras. Quando lhe é perguntado com quem ela mora, ela prontamente responde: "Eu moro com a minha mãe!". Contudo, ao ser indagada sobre a exclusão dos avós maternos e a inclusão dos avós paternos no seu desenho da família (Figura 12) ela explica: "Porque a minha avó materna, eu não moro com ela, então eu não me sinto tão próxima".

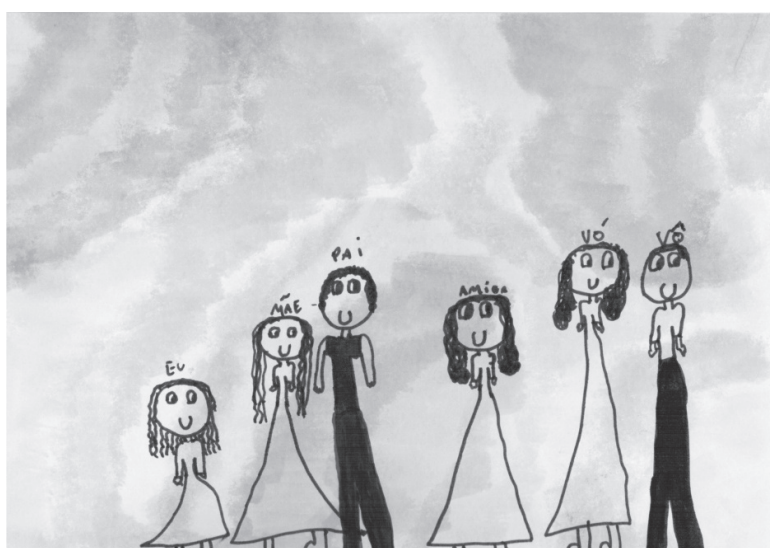

Figura 12: Desenho da família de Melissa, que inclui seus avós paternos, mas não os maternos, por serem aqueles que sempre cuidam dela.
0 fato dela "fazer os temas, fazer tudo e só depois ir pra casa da mãe" faz com que ela se sinta confusa em relação ao lugar em que ela mora: "Pra mim eu moro com a minha mãe né, mas a minha vó e o meu vô, eu... mas eu....' No fragmento de sua representação cartográfica, podemos observar que ela escreveu "eu" nos dois edifícios, mostrando residir em ambos os espaços. Para Melissa, as fronteiras entre a casa de sua mãe e a casa de seus avós são bastante tênues, fazendo com que ela se sinta confusa em relação ao seu "verdadeiro" lar. Para ela, assim como para muitas outras crianças, a pergunta "com quem e onde tu moras" não é uma pergunta necessariamente fácil de ser respondida:

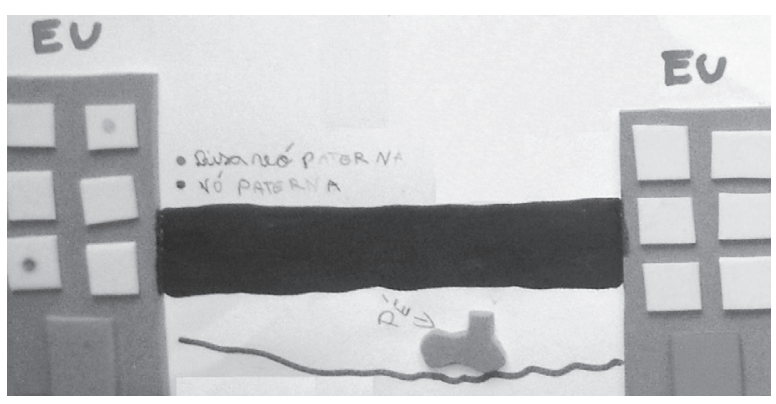

Figura 13: Fragmento da representação cartográfica de Melissa. Podemos ver, à direita, a casa da avó; à esquerda, o edifício no qual ela mora com a mãe.

Melissa [10 anos] - A minha mãe não gosta que ninguém pense que eu moro com a minha avó, porque eu quase moro com a minha avó... Pra mim, a minha avó, bah! Se não tivesse a minha avó eu não sei o que seria! A minha avó, ela faz tudo: ela me leva na psicóloga, na psicopedagoga, no colégio... Ela faz tudo! Se não fosse a minha avó eu não sei, porque a minha mãe tem que trabalhar. [...] Mesmo que eu não fique todas as noites, eu fico com ela quase toda a hora... Eu fico lá de manhã, até eu ir pra escola. A escola não conta. Daí eu volto da escola e fico lá e daí eu só saio de lá depois de fazer o tema, depois de fazer tudo! Então, tudo o que eu faço é com a minha avó! Com a minha mãe são só poucas coisas que eu faço... [...] é, eu acho mesmo que eu moro com os dois. É, eu acho que eu moro com a minha mãe e com os meus avós... Pra mim eu moro com os dois! Tá! Todo mundo!

\section{Referencias bibliográficas}

Attias-Donfut, C. (2002). Des Générations solidaires. En Dortier, J. F., Familles: permanence et métamorphoses (pp. 113-123). France: Sciences Humaneis.

Camarano, A. A. (2006). Envelhecimento da população brasileira: uma contribuição demográfica. En Freitas, E. V. et al. (Eds.), Tratado de Geriatria e Gerontologia (pp. 88-105). Rio de Janeiro: Guanabara Koogan. 
Camarano, A. A.; Kanso, S.; Mello, J. L. (2004). Como vive o idoso brasileiro? En Camarano, A. A. (Ed.), Os novos idosos brasileiros: muito além dos 60? (pp. 77-106). Rio de Janeiro: IPEA.

Camarano, A. A.; Kanso, S.; Mello, J. L.; Pasinato, M. T. (2004a). Família: espaço de compartilhamento de recursos e vulnerabilidades. En Camarano, A. A. (Eds.), Os novos idosos brasileiros: muito além dos 60? (pp. 137-168). Rio de Janeiro: IPEA.

Casper, Lynne M.; Bryson, Kenneth R. (1998). Co-resident Grandparents and Their Grandchildren: Grandparent Maintained Families. U.S. Census Bureau. Population Division Working Paper, 26.

Fundação Perseu Abramo (2007). Idosos no Brasil: vivências, desafios e expectativas na terceira idade. Retrieved from: http://www.fpabramo.org.br/portal/.

Goodman, C. C. (2007). Family Dinamics in Three-Generation Grandfamilies. Journal of Family, Issues, 28(3), 355-379.

Instituto Brasileiro de Geografia e Estatística (2004). Síntese de Indicadores Sociais 2003. Comunicação Social, 13 abr. 2004. Retrieved from http://www.ibge.gov.br.

International Labour Organization (2011). Retrieved from: http://www.oit.org.br.

Landry-Meyer, L.; Newman, B. M. (2004). An Exploration of the Grandparent Caregiver Role. Journal of Family, 25(8), 1005-1025.

Lins De Barros, M. (1987). Autoridade e Afeto: avós, filhos e netos na família brasileira. Rio de Janeiro: Jorge Zahar.

Pebley, A. R.; Rudkin, L. L. (1999). Grandparents Caring for Grandchildren: what do we know? Journal of Family, $20(2), 218-242$.

Peixoto, C. E. (2004). Aposentadoria: retorno ao trabalho e solidariedade familiar. En (Ed.), Família e envelhecimento (pp. 57-84). Rio de Janeiro: FGV.

Peixoto, C. E.; Luz, G. M. (2007). De uma morada à outra: processos de re-coabitação entre as gerações. Cadernos Pagu, 29, 171-191.

Ramos, A. C. (2011). Meus avós e eu: as relações intergeracionais entre avós e netos na perspectiva das crianças. Porto Alegre: UFRGS, 2011. 464 p. Tese (Doutorado em Educação). Faculdade de Educacao. Universidade Federal do Rio Grande do Sul, Porto Alegre, 2011.

Scott, J. (2008). Children as Respondents: the Challenge for Quantitative Methods. En Christensen, Pia; James, A. (Eds.), Research with children: Perspectives and Practices. 2nd. ed. (pp. 87-108). New York: Routledge.

U.S. Census Bureau (2010). Retrieved from: http://www. census.gov/. 